\title{
Natural Frequencies of Internally-Doubly-Tapered Laminated Composite Beams
}

\author{
Amin Fazili \\ Department of Mechanical, Industrial \& Aerospace \\ Engineering \\ Concordia University \\ Montreal, Canada
}

\author{
Rajamohan Ganesan \\ Department of Mechanical, Industrial \& Aerospace \\ Engineering \\ Concordia University \\ Montreal, Canada
}

\begin{abstract}
In the present study, the free vibration response of symmetric thickness-and-width-tapered (doubly-tapered) laminated composite beams is investigated. Considering the continuous-plies-interspersed ply drop-off configuration, called herein as taper configuration $\mathrm{D}$, both conventional and hierarchical finite element formulations are developed based on the cylindrical bending theory of laminated beam. Natural frequencies of different types of internally-tapered composite beams are determined. Comparison of the hierarchical finite element solution with the Rayleigh-Ritz solution and a higherorder finite element solution is performed. A parametric study is conducted to investigate the effects of width-taper-ratio and the thickness-taper-ratio (or equivalently thickness-tapering angle) on the free vibration response of doubly-tapered laminated composite beams.
\end{abstract}

Keywords: Tapered Composite Beam, Free Vibration, Hierarchical Finite Element Method, Natural Frequencies

\section{INTRODUCTION}

Composite material refers to material that is created by the synthetic assembly of two or more organic or inorganic materials in order to obtain specific material properties such as high strength and stiffness to weight ratios, corrosion resistance, thermal properties, fatigue life, wear resistance and increased tolerance to damage [1]. In some specific applications of composite structures such as helicopter yoke or turbine blades, the laminate needs to be stiff at one location and flexible at another location. This type of structure is created by terminating or dropping-off selected plies at specific locations to reduce the stiffness, and is called as the tapered composite structure [2].

Finite Element Method (FEM) is one of the most accurate and powerful tools used to study the response of complex mechanical structures such as the vibration of laminated composite beams. The convergence and accuracy of the results determined using finite element formulation depend strongly on the selected type of element. The type of element that is considered for the finite element formulation in this study has two degrees of freedom per node (deflection and rotation) and two nodes per element. In Conventional Finite Element Method (CFEM), interpolation or shape functions are determined based solely on these degrees of freedom. In the Hierarchical Finite Element Method (HFEM), a number of trigonometric terms are added to these interpolation functions in a hierarchical manner.

There are several studies on the free vibration of laminated composite beams, mostly on the subject of uniform-thickness uniform-width beams. Free vibration of uniform laminated composite beams was studied by Abarcar and Caniff [3], Chandrashekhara et al. [4], Marur and Kant [5] and Miller and Adams [6]. Reddy [7], Berthelot [8], Whitney [9], and Jones [10] have given the exact solutions for the free vibrations of uniform laminated composite beams. Vinson and Sierakowski [11] determined the exact natural frequencies of a simply-supported uniform composite beam based on classical laminate theory.

There are selectively few studies conducted on tapered composite beams. He et al. [12] have conducted a review of the works on tapered laminated composite structures. Ganesan and Zabihollah have studied thickness-tapered laminated composite beams $[13,14]$ using a higher-order but conventional finite element formulation and performed a parametric study. Ahmed [2] has studied and conducted experiments on free and forced vibration response of thickness-tapered composite beams including the effects of axial force and damping. Badagi [15] conducted the free and forced vibration analysis of thicknessand-width-tapered laminated composite beams using RayleighRitz method. Farghaly and Gadelrab [16] have studied the free vibration of stepped uniform-width thickness-tapered Timoshenko composite beams. Salajegheh and Ganesan [17] have studied the vibrations of thickness-and-width-tapered laminated composite beams with rigid and elastic supports using a higher-order but conventional finite element.

Hierarchical Finite Element Method (HFEM) has been used in the following works. Zienkiewicz [18], Cook [19] and Reddy [20] have described the use of HFEM to analyze the vibration of metallic and composite beams. Ganesan and Chen [21] have studied the free vibration response of thickness-tapered composite beams using HFEM and Rayleigh-Ritz method. Lees and Thomas [22] conducted a modal analysis on a clampedclamped Timoshenko beam using HFEM. Bardell [23] conducted a free vibration analysis of a rectangular plate using the HFEM. Yu et al. [24] studied a multivariable HFEM for static and vibration analysis of beams. Ribeiro and Petyt [25] 
studied the non-linear free and forced vibrations of composite laminated plates using HFEM.

It is learnt that although there are several works on the study of uniform composite beams, works on the vibration of tapered composite beams are scarce to find in the literature. Also, due to its accuracy and efficiency, HFEM seems the appropriate choice to employ for vibration analysis of composite beams. In the present work, doubly-tapered composite beam is studied for its free vibration response using HFEM.

\section{FINITE ELEMENT FORMULATION}

The composite beam has a large length-to-thickness ratio as shown in Fig. 1, and therefore by applying the cylindrical bending theory and considering classical laminate theory, one can get the equation of motion in variational form as:

$\int_{0}^{L} b(x) D_{11}(x)\left(\frac{\mathrm{d}^{2} w}{\mathrm{~d} x^{2}}\right)\left(\frac{d^{2} \delta w}{\mathrm{~d} x^{2}}\right) d x-\int_{0}^{L} b(x) N_{x}\left(\frac{\mathrm{d} w}{\mathrm{dx}}\right)\left(\frac{\mathrm{d} \delta w}{\mathrm{dx}}\right) d x$

$-\omega^{2} \int_{0}^{L} \int_{-H / 2}^{H / 2} \rho b(x) w \delta w d x d z=0$

In which it is assumed that the deflection in (transverse) $\mathrm{z}$ direction can be expressed as:

$w(x, t)=W(x) e^{i \omega t}$

In (1), $L$ is the length of the beam, $b(x)$ is the width of the beam at each cross section along the length of the tapered part of the beam $\left(b(x)=\left(b_{R}-b_{L}\right) x / L+b_{L}\right), N_{x}$ is the compressive axial force (if present), $H$ is the thickness of the beam, $\rho$ is the beam density. $D_{11}(x)$ is the coefficient of bending stiffness of the laminated composite beam [8] and it can be calculated as:

$D_{11}(x)=\sum_{k=1}^{n}\left[t_{k} z_{k}^{2}-\frac{t_{k}^{3}}{12}\right]\left(\bar{Q}_{11}\right)_{k}$

where $t_{k}$ denotes the thickness of $k^{\text {th }}$ ply and $\left(\bar{Q}_{11}\right)_{k}$ denotes the transformed reduced stiffness coefficient of the $k^{\text {th }}$ ply.

\section{A. CFEM formulation}

In Conventional Finite Element Method (CFEM), the structure is divided into a number of Euler-Bernoulli beam elements. Each element can have a number of nodes, which are the critical points. In this study, two nodes per element and two degrees of freedom per node are used in the formulation as shown in Fig. 1.

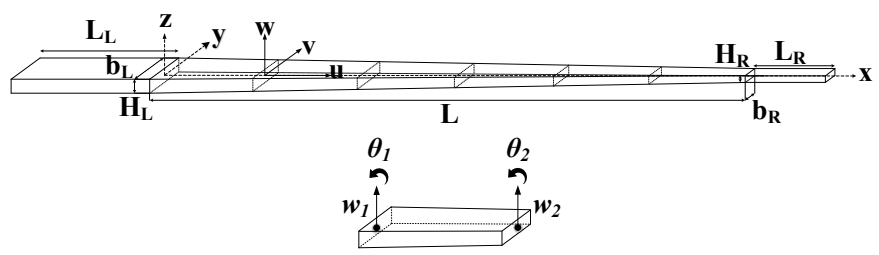

Figure 1. Global and local co-ordinates (top), and nodal displacements and rotations (bottom)
Having four degrees of freedom per element, a third-order polynomial is required for the expression of deflection to satisfy the boundary conditions as below:

$W(x)=c_{1}+c_{2} x+c_{3} x^{2}+c_{4} x^{3}$

After determining and using corresponding interpolation functions and following the CFEM, the equation of motion becomes:

$$
\begin{aligned}
& {\left[\int_{0}^{l_{e}} b(x)\left[D_{11}\left[N^{M}\right]^{T}\left[N^{M}\right]-N_{x}\left[N^{d}\right]^{T}\left[N^{d}\right]\right] d x\right.} \\
& \left.-\omega^{2} \int_{0}^{l_{e}} b(x)\left(\rho_{p} H_{p}+\rho_{r} H_{r}\right)\left[N^{w}\right]^{T}\left[N^{w}\right] d x\right]\{u\}=0
\end{aligned}
$$

In (5), $\left[N^{w}\right]$ is the shape function matrix and $\left[N^{d}\right]$ and $\left[N^{M}\right]$ are the first and second derivatives of $\left[N^{w}\right]$, respectively. $\rho_{p}$ is the density of the ply, $\rho_{r}$ is the density of resin, $l_{e}$ is the length of the element and $H_{p}$ and $H_{r}$ are the equivalent thicknesses of the resin and ply in each element, respectively. For example, if an element has a cross-sectional area of $A=A_{P l y}+A_{\text {Resin }}$ and element length of $l_{e}$, therefore $H_{p}=A_{P l y} / l_{e}$ and $H_{r}=A_{\text {Resin }} /$ $l_{e}$.

Stiffness $[k]$ and mass $[m]$ matrices are defined for each element as:

$$
\begin{aligned}
& {[k]=\int_{0}^{l_{e}} b(x)\left[D_{11}(x)\left[N^{M}\right]^{T}\left[N^{M}\right]-N_{x}\left[N^{d}\right]^{T}\left[N^{d}\right]\right] d x} \\
& {[m]=\int_{0}^{L} b(x)\left(\rho_{p} H_{p}+\rho_{r} H_{r}\right)\left[N^{w}\right]^{T}\left[N^{w}\right] d x}
\end{aligned}
$$

One can assemble global stiffness $[K]$ and mass $[M]$ matrices of the beam using element matrices by enforcing deflection and rotation continuity conditions. As a result, (5) transforms into:

$\left[[K]-\omega^{2}[M]\right]\{u\}=0$

Equation (8) is an eigenvalue problem and can be solved to determine the natural frequencies and mode shapes of the beam.

\section{B. HFEM formulation}

In the CFEM formulation, a cubical displacement function was assumed in Equation (4). In the Hierarchical Finite Element Method (HFEM) the displacement function is modified by adding trigonometric or polynomial functions [7]. In this study, the trigonometric hierarchical functions are used as:

$W(x)=c_{1}+c_{2} x+c_{3} x^{2}+c_{4} x^{3}+\sum_{i=1}^{N} c_{i+4} \sin \frac{i \pi x}{l_{e}}, \quad i=1,2,3, \ldots$

in which $l_{e}$ is the length of the element and $N$ is the number of hierarchical terms. Equation (9) can be expressed as:

$$
\begin{aligned}
& W=\left[K_{w}\right][c] \\
& K_{w}=\left[\begin{array}{llllll}
1 & x & x^{2} & x^{3} \sin \frac{\pi x}{l_{e}} \ldots \sin \frac{N \pi x}{l_{e}}
\end{array}\right]
\end{aligned}
$$


$[c]=\left[\begin{array}{c}c_{1} \\ c_{2} \\ c_{3} \\ c_{4} \\ c_{5} \\ \vdots \\ c_{N+4}\end{array}\right]$

In the same manner, rotation $(\theta)$ can be expressed as:

$\theta=\left[K_{\theta}\right][c]$

$K_{\theta}=\frac{d\left(K_{w}\right)}{d x}=\left[\begin{array}{llllll}0 & 1 & 2 x & 3 x^{2} & \frac{\pi}{l_{e}} \cos \frac{\pi x}{l_{e}} \ldots \frac{N \pi}{l_{e}} \cos \frac{N \pi x}{l_{e}}\end{array}\right]$

The displacement matrix in local coordinate system is:

$\{u\}=\left\{\begin{array}{c}w_{1} \\ \theta_{1} \\ w_{2} \\ \theta_{2} \\ A_{1} \\ \vdots \\ A_{N}\end{array}\right\}=\left[K_{u}\right]\{c\}$

in which $A_{\mathrm{i}}$ are the hierarchical degrees of freedom corresponding to hierarchical terms and $\left[K_{u}\right]$ can be written as [21]:

$\left[K_{u}\right]=\left[\begin{array}{ccccccc}1 & 0 & 0 & 0 & 0 & \ldots & 0 \\ 0 & 1 & 0 & 0 & \frac{\pi}{l_{e}} & \ldots & \frac{N \pi}{l_{e}} \\ 1 & l_{e} & l_{e}^{2} & l_{e}^{3} & 0 & \ldots & 0 \\ 0 & 1 & 2 l_{e} & 3 l_{e}^{2} & -\frac{\pi}{l_{e}} & \ldots & (-1)^{N} \frac{N \pi}{l_{e}} \\ 0 & 0 & 0 & 0 & 1 & \ldots & 0 \\ \vdots & \vdots & \vdots & \vdots & \vdots & \ddots & \vdots \\ 0 & 0 & 0 & 0 & 0 & \ldots & 1\end{array}\right]$

The procedure to determine the stiffness [k] and mass [m] matrices for each element from the variational statement of equations of motion, (1), is analogous to that described for CFEM. The algorithm to assemble the global stiffness $[K]$ and global mass $[M]$ matrices is described in the Appendix.

Table I. Material Properties

\begin{tabular}{|c|c|c|c|}
\hline \multicolumn{2}{|c|}{ Mechanical properties of ply } & \multicolumn{2}{|c|}{ Mechanical properties of resin } \\
\hline Longitudinal modulus $\left(\mathrm{E}_{1}\right)$ & $113.9 \mathrm{GPa}$ & Elastic Modulus (E) & $3.93 \mathrm{GPa}$ \\
\hline Transverse modulus $\left(\mathrm{E}_{2}\right)$ & $7.985 \mathrm{GPa}$ & Shear modulus (G) & $1.03 \mathrm{GPa}$ \\
\hline $\mathrm{E}_{3}=\mathrm{E}_{2}$ & $7.985 \mathrm{GPa}$ & Poisson's ratio $(v)$ & 0.37 \\
\hline In-plane shear modulus $\left(\mathrm{G}_{12}\right)$ & $3.138 \mathrm{GPa}$ & Density of resin $(\rho r)$ & $1000 \mathrm{~kg} / \mathrm{m}^{3}$ \\
\hline Major Poisson's ratio $\left(v_{12}\right)$ & 0.288 & & \\
\hline Minor Poisson's ratio $\left(v_{21}\right)$ & 0.178 & & \\
\hline Density of ply $\left(\rho_{p}\right)$ & $1480 \mathrm{~kg} / \mathrm{m}^{3}$ & & \\
\hline
\end{tabular}

\section{FREE VIBRATION ANALYSIS AND DISCUSSION}

\section{A. Validation and convergence of HFEM solution}

The material chosen in this study is NCT-301 graphite-epoxy prepreg which is available in the laboratory of Concordia Centre for Composites (CONCOM). The mechanical properties of the ply and the resin are given in the Table I. The beam has [0/90]gs laminate configuration unless specified otherwise.

In order to validate the HFEM formulation, a uniformthickness uniform-width laminated composite beam is considered. The beam is composed of 36 plies. Individual ply thickness $\left(t_{k}\right)$ is $0.125 \mathrm{~mm}$ and the beam thickness $(H)$ is $4.5 \mathrm{~mm}$. Free vibration analysis is carried out using both CFEM and HFEM for clamped-free boundary condition.
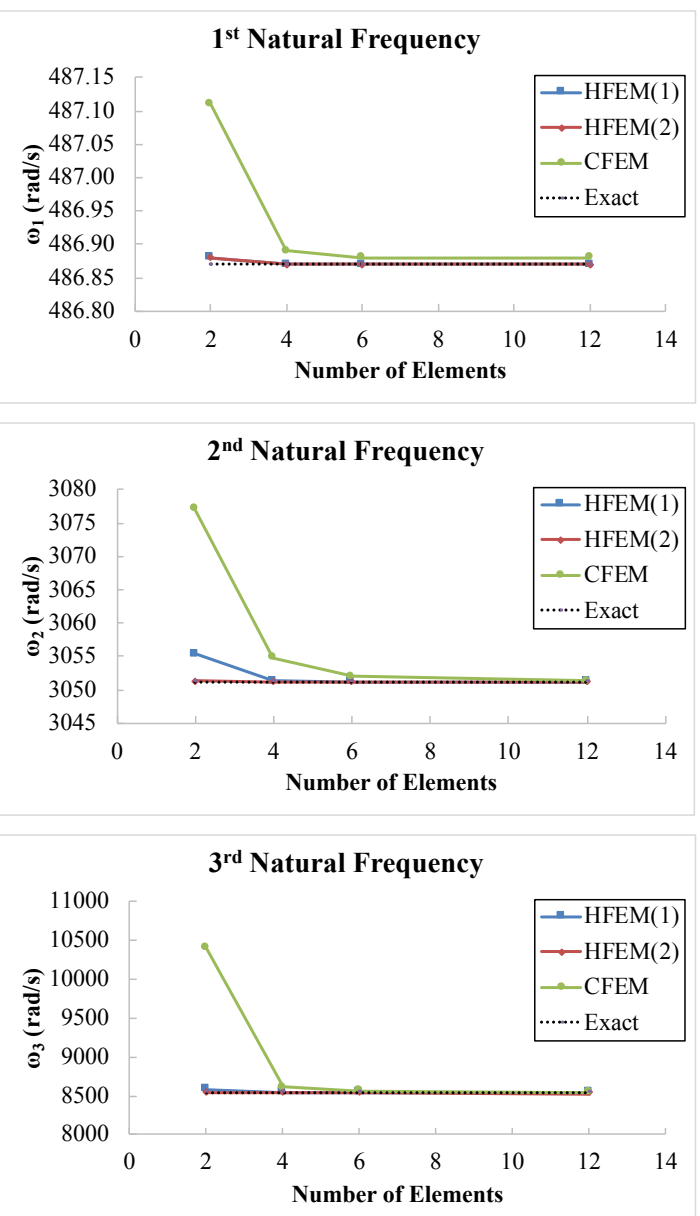

Figure 2. The comparison between results obtained using CFEM and HFEM

The first three natural frequencies are given in Fig. 2 for CFEM, HFEM with one hierarchical term $(\operatorname{HFEM}(1))$ and HFEM with two hierarchical term $(\operatorname{HFEM}(2))$ alongside the exact values of the natural frequencies [8].

As it is shown in Fig. 2, HFEM provides a better accuracy than CFEM with less number of elements that will significantly reduce the time required for the computations and reduce significantly the discontinuities in stress distributions across the nodes. In addition, there is no significant difference between the 
results when the second hierarchical term is added. As a result, in this study HFEM with one trigonometric hierarchical term is considered.

In order to validate the accuracy of the HFEM model, a comparison with the results obtained using R-R (Rayleigh-Ritz method) [15] and a HOFEM (Higher-Order Finite Element Method) [17] is performed. The values of the first three natural frequencies using HFEM are presented alongside the results obtained using R-R and HOFEM methods in Table A.I in Appendix.

The comparison shows that HFEM provides accurate results within $0.2 \%$ of difference from the above-mentioned methods, which is very acceptable and appealing.

\section{B. Parametric Study}

As shown in Figure 3 (not to scale), a thickness-and-widthtapered composite beam composed of 36 plies at the thick (left) side and 12 plies at the thin (right) side, is considered. Thickness of each ply is $0.125 \mathrm{~mm}$ and therefore the thick side beam thickness is $4.5 \mathrm{~mm}$ as opposed to $1.5 \mathrm{~mm}$ beam thickness at the thin side. The beam has a width of $15 \mathrm{~mm}$ at the wide section $\left(b_{L}\right)$ and $7.5 \mathrm{~mm}$ at the narrow section $\left(b_{R}\right)$, which leads to a width-taper-ratio $\left(b_{R} / b_{L}\right)$ of 0.5 . The beam has a length of $25 \mathrm{~cm}$ and $[0 / 90]_{9 s}$ laminate configuration. The material properties are given in Table I. The beam has a simply supported boundary condition.

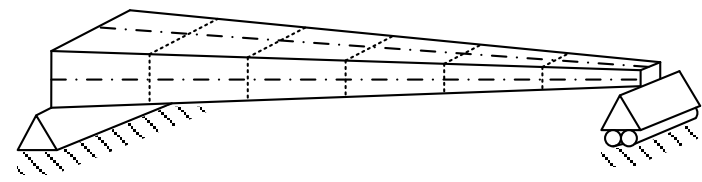

Figure 3. Doubly-tapered composite beam in simply-supported boundary condition

The following is a parametric study to determine the effect tapering on natural frequencies. In each section one variable is considered while all other variables remain constant with the values mentioned above as the base values.

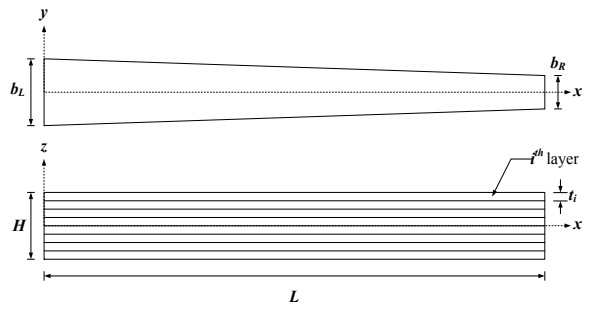

Figure 4. Uniform-thickness and width-tapered composite beam

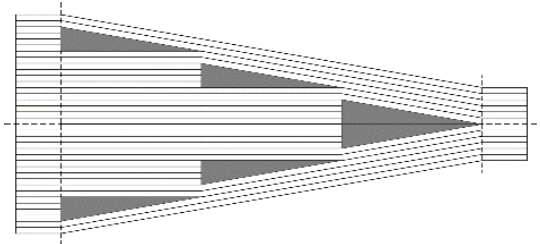

Figure 5. Thickness-taper configuration D
First, the effect of width-tapering, as shown in Figure 4 (not to scale), on the first three natural frequencies is considered. Then, the effect of thickness-tapering for taper configuration D, as shown in Figure 5 (not to scale), on the first three natural frequencies is investigated. Finally, the first three natural frequencies are calculated for a doubly-tapered composite beam.

\section{Discussion}

Figure 6 shows the effect of width-taper-ratio on the natural frequency ratio of a uniform-thickness and width-tapered composite beam, for the first three natural frequencies. Natural frequency change is the ratio of the corresponding natural frequency for a given width-taper-ratio minus natural frequency of the uniform composite beam over the natural frequency of the uniform composite beam. As it is shown in Figure 6, The first natural frequency slightly decreases as the width-taper-ratio decreases. However, even by having a width-taper-ratio of $1 / 3$, only $1.06 \%$ decrease is observed. However, For the second and third natural frequencies, by decreasing the width-taper-ratio, the natural frequencies slightly increase (less than $0.2 \%$ ).

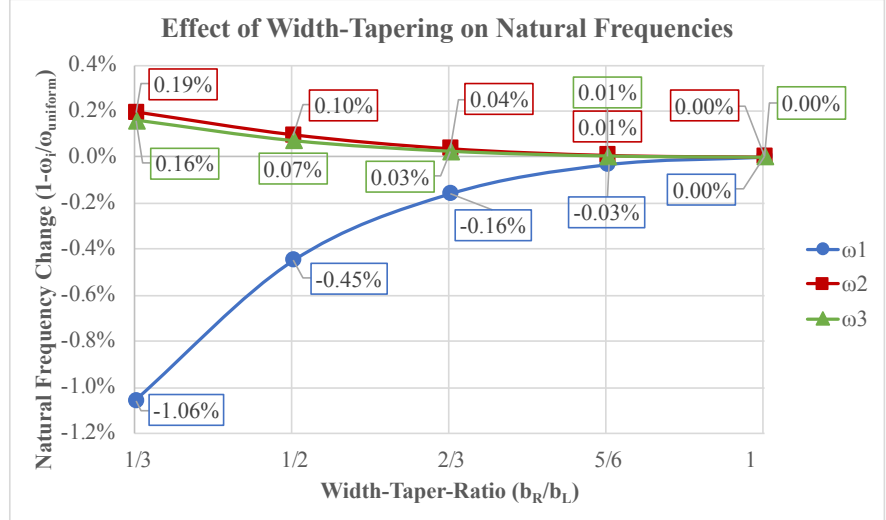

Figure 6. Effect of width-taper-ratio on the first three natural frequencies

In Figure 7, the effect of thickness-tapering on the natural frequencies of thickness-tapered composite beams is plotted. Here, the natural frequency change is the ratio of the corresponding natural frequency for a given thickness-ratio minus natural frequency of the uniform composite beam over the natural frequency of the uniform composite beam. Thicknessratio is the ratio of the thickness of the thin side over the thickness of the thick side. For this study thickness ratios of $1 / 3$, $1 / 2,2 / 3,5 / 6$ and 1 are considered which corresponds to thickness-taper angles of $0.344^{\circ}, 0.258^{\circ}, 0.172^{\circ}, 0.086^{\circ}$ and $0^{\circ}$, respectively. As it is shown in Figure 7, as the thickness ratio decreases, the first natural frequency decreases drastically. For a thickness ratio of $1 / 3$ (or equivalently thickness-taper angle of $0.344^{\circ}$ ), the first natural frequency decreases by $39.82 \%$. The second and the third natural frequencies show similar drastic reductions. This can be interpreted by the fact that by removing ply material along the thickness of the composite beam, the value of $\mathrm{D}_{11}$ decreases cubically, which results in the drastic reduction of stiffness of the beam. Moreover, thickness-tapering introduces packets of resin along the thickness of the beam which would also result in the decrease in stiffness of the beam and consequently the decrease of the natural frequencies. 


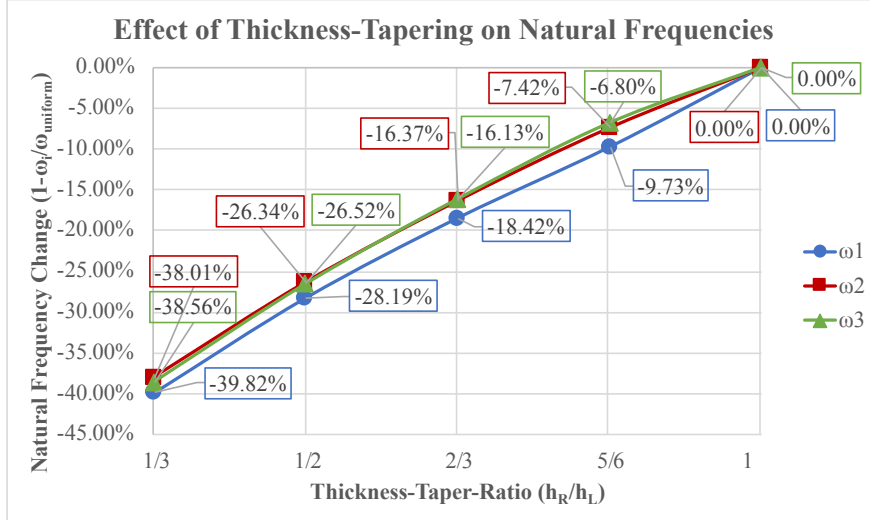

Figure 7. Effect of thickness-taper-ratio (or equivalently thickness-taperangle) on the first three natural frequencies

Figure 8, shows the effect of width-tapering on a thicknesstapered composite beam with the thickness ratio of $1 / 3$ (or equivalently thickness-taper angle of $0.344^{\circ}$ ). It can be seen from Figure 8 that by having no width-tapering (width-taperingratio $=1$ ) the reduction of $39.82 \%$ in the first natural frequency is present. By decreasing the width-tapering-ratio we see an additional decrease in natural frequencies (up to $3.27 \%$ for width-taper-ratio $=1 / 3$ ). However, as it was observed before, the second and the third natural frequencies are slightly increased (less than $0.9 \%$ compared to the case of thicknesstapered-only) by decreasing the width-taper-ratio.

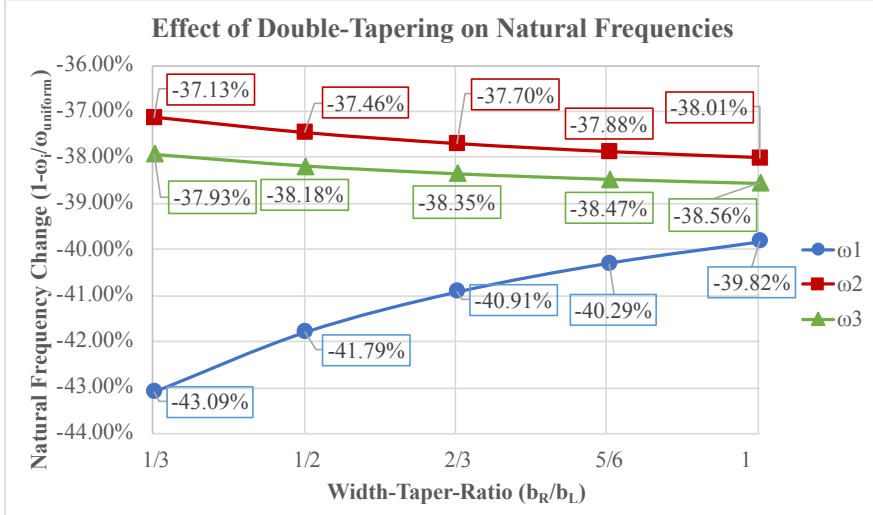

Figure 8. Effect of double-tapering on the first three natural frequencies thickness-taper-ratio $=1 / 3$

\section{CONCLUSION}

Hierarchical Finite Element Method (HFEM) provides a better accuracy than Conventional Finite Element Method (CFEM) with less number of elements and this will significantly reduce especially the stress/strain discontinuities across nodes. In addition, there is no significant difference between the results when the second hierarchical term is added. Moreover, a comparison with other published results obtained using R-R (Rayleigh-Ritz method) and a HOFEM (HigherOrder Finite Element Method) shows that HFEM provides accurate results within $0.2 \%$ of difference from the abovementioned methods, which is very acceptable.

A parametric study on the effect of boundary conditions, width-taper-ratio and thickness-taper-ratio (or equivalently thickness-taper angle on the free vibration response of doublytapered laminated composite beams is conducted and the following are concluded:

- Width-tapering has a small effect $(1 \%$ decrease for a width-taper-ratio of 1/3) on first natural frequency of a simply supported composite beam. This effect is even less significant for the second and the third natural frequencies (less than $0.2 \%$ increase).

- Thickness-tapering on the other hand has a significant effect $(9.73 \%$ decrease for thickness-taper-ratio of $5 / 6$ $39.82 \%$ decrease for thickness-taper-ratio of $1 / 3$ ) on the first natural frequency of a simply supported composite beam. This effect is similar for the second and the third natural frequencies.

- Addition of width-tapering to a thickness-tapered composite beam has a slight effect on its first natural frequency $(1.97 \%$ decrease for width-taper-ratio of $1 / 2)$. However, this effect is insignificant on the second and the third natural frequencies $(0.54 \%$ and $0.38 \%$ increase, respectively).

\section{REFERENCES}

[1] O. O. Ochoa and J. N. Reddy, "Finite element analysis of composite laminates," Dordrecht; Boston: Kluwer Academic Publishers, 1992.

[2] H. E. U. Ahmed, "Free and forced vibrations of tapered composite beams including the effects of axial force and damping," Montreal: Concordia Universty, 2008.

[3] R. B. Abarcar and P. F. Cunniff, "The vibration of cantilever beams of fiber reinforced material," Journal of Composite Materials, vol. 6, pp. 504-517, 1972.

[4] K. Chandrashekhara, K. Krishnamurthy, and S. Roy, "Free vibration of composite beams including rotary inertia and shear deformation," Composite Structures, vol. 14, pp. 269-279, 1990.

[5] S. R. Marur and T. Kant, "Free vibration analysis of fiber reinforced composite beams using higher order theories and finite element modelling," Journal of Sound and Vibration, vol. 194, pp. 337-351, 1996.

[6] A. K. Miller and D.F. Adams, "An analytic means of determining the flexural and torsional resonant frequencies of generally orthotropic beams," Journal of Sound and Vibration, vol. 41, pp. 433-449, 1975.

[7] J. N. Reddy, "Mechanics of laminated composite plates and shells : theory and analysis," Boca Raton: CRC Press, 2004.

[8] J. M. Bertholet, "Composite materials : mechanical behavior and structural analysis," New York: Springer, 1999.

[9] J. M. Whitney and J. E. Ashton, "Structural analysis of laminated anisotropic plates," Lancaster, Pa., U.S.A.: Technomic Pub. Co., 1987.

[10] R. M. Jones, "Mechanics of composite materials," Philadelphia, PA: Taylor \& Francis, 1999.

[11] Vinson, Jack R., and Robert L. Sierakowski. "The behavior of structures composed of composite materials", vol. 105. Springer Science \& Business Media, 2006.

[12] K. He, S. V. Hoa, and R. Ganesan, "The study of tapered laminated composite structures: a review," Composites Science and Technology, vol. 60, pp. 2643-2657, 11// 2000.

[13] R. Ganesan, A. Zabihollah, "Vibration analysis of tapered composite beams using a higher-order finite element. Part I: Formulation," Composite Structures, vol. 77, pp. 306-318, 2007.

[14] R. Ganesan, A. Zabihollah, "Vibration analysis of tapered composite beams using a higher-order finite element. Part II: parametric study," Composite Structures, vol. 77, pp. 319-330, 2007.

[15] V. K. Badagi, "Dynamic response of width- and thickness-tapered composite beams using Rayleigh- Ritz method and modal testing," Montreal: Concordia University, 2012. 
[16] S. H. Farghaly, R. M. Gadelrab, "Free vibration of a stepped composite timoshenko cantilever beam," Journal of Sound and Vibration, vol. 187, pp. 886-896, 1995.

[17] P. Salajegheh, R. Ganesan, "Finite element vibration analysis of variablethickness variable-width laminated composite beams," 27th Annual Technical Conference of the American Society for Composites, Arlington, TX, United States: pp. 1307-1320, 2012.

[18] O. C. Zienkiewicz, "The Finite Element Method," London; New York: McGraw-Hill, 1977.

[19] R. D. Cook, D. S. Malkus, and M. E. Plesha, "Concepts and applications of finite element analysis," New York: Wiley, 1989.

[20] J. N. Reddy, "An introduction to the finite element method," New York: McGraw-Hill, 1993.
[21] R. Ganesan, L. Chen, "Vibration analysis of tapered composite beams using hierarchical finite element and three-dimensional ply stiffness analysis," International Conference on Resource Utilisation and Intelligent Systems (INCRUIS-2006), Erode, India 2006.

[22] A. W. Lees, D. L. Thomas, "Modal hierarchical Timoshenko beam finite elements," Journal of Sound and Vibration, vol. 99, pp. 455-461, 1985.

[23] N. S. Bardell, "Free vibration analysis of a flat plate using the hierarchical finite element method," Journal of Sound and Vibration, vol. 151, pp. 263$289,1991$.

[24] Z. Yu, X. Guo, F. Chu, "A multivariable hierarchical finite element for static and vibration analysis of beams," Finite Elements in Analysis and Design, vol. 46, pp. 625-631, 2010.

[25] P. Ribeiro, M. Petyt, "Non-linear vibration of composite laminated plates by the hierarchical finite element method," Composite Structures, vol. 46, pp. 197-208, 1999.

\section{APPENDIX}

Table A.I. Comparison between the natural frequencies obtained using HFEM, HOFEM and R-R method for different width-taper-ratios $\left(\mathrm{b}_{\mathrm{L}}=1.66 \mathrm{~cm}\right)$

\begin{tabular}{|c|c|c|c|c|c|c|c|c|c|c|c|}
\hline & \multicolumn{5}{|c|}{$\mathrm{b}_{\mathrm{R}} / \mathrm{b}_{\mathrm{L}}=0.4$} & \multicolumn{5}{|c|}{$\mathrm{b}_{\mathrm{R}} / \mathrm{b}_{\mathrm{L}}=0.6$} \\
\hline & & R-R [15] & $\begin{array}{c}\text { HOFEM } \\
{[17]}\end{array}$ & HFEM & $\begin{array}{l}\text { Difference } \\
\text { with } \\
\text { R-R (\%) }\end{array}$ & $\begin{array}{c}\text { Difference } \\
\text { with } \\
\text { HOFEM (\%) }\end{array}$ & R-R & HOFEM & HFEM & $\begin{array}{c}\text { Difference } \\
\text { with } \\
\text { R-R (\%) }\end{array}$ & $\begin{array}{c}\text { Difference } \\
\text { with } \\
\text { HOFEM (\%) }\end{array}$ \\
\hline \multirow[t]{2}{*}{$\mathrm{S}-\mathrm{S}$} & $\omega_{2}(\mathrm{rad} / \mathrm{s})$ & 5085.7 & 5091.9 & 5092.02 & 0.12 & 0.00 & 5081.5 & 5087.07 & 5087.18 & 0.11 & 0.00 \\
\hline & $\omega_{3}(\mathrm{rad} / \mathrm{s})$ & 11439 & 11453.15 & 11455.45 & 0.14 & 0.02 & 11432 & 11444.15 & 11446.53 & 0.13 & 0.02 \\
\hline \multirow[t]{2}{*}{$\mathrm{C}-\mathrm{C}$} & $\omega_{2}(\mathrm{rad} / \mathrm{s})$ & 7873.7 & 7883.45 & 7883.8 & 0.13 & 0.00 & 7915.2 & 7923.87 & 7924.32 & 0.12 & 0.01 \\
\hline & $\omega_{3}(\mathrm{rad} / \mathrm{s})$ & 15485 & 15504.47 & 15511.12 & 0.17 & 0.04 & 15533 & 15549.98 & 15557.16 & 0.16 & 0.05 \\
\hline \multirow[b]{2}{*}{ C-F } & $\omega_{1}(\mathrm{rad} / \mathrm{s})$ & 589.8 & 590.5 & 590.52 & 0.12 & 0.00 & 527.05 & 527.62 & 527.63 & 0.11 & 0.00 \\
\hline & $\omega_{2}(\mathrm{rad} / \mathrm{s})$ & 3089.8 & 3093.44 & 3093.58 & 0.12 & 0.00 & 2974.1 & 2977.28 & 2977.36 & 0.11 & 0.00 \\
\hline $\mathrm{F}-\mathrm{C}$ & $\omega_{3}(\mathrm{rad} / \mathrm{s})$ & 7708.9 & 7718.54 & 7718.95 & 0.13 & 0.01 & 7809.6 & 7818.32 & 7818.89 & 0.12 & 0.01 \\
\hline & & \multicolumn{5}{|c|}{$\mathrm{b}_{\mathrm{R}} / \mathrm{b}_{\mathrm{L}}=0.8$} & \multicolumn{5}{|c|}{$\mathrm{b}_{\mathrm{R}} / \mathrm{b}_{\mathrm{L}}=1$} \\
\hline & & $\mathrm{R}-\mathrm{R}$ & HOFEM & HFEM & $\begin{array}{l}\text { Difference } \\
\text { with } \\
\text { R-R }(\%) \\
\end{array}$ & $\begin{array}{c}\text { Difference } \\
\text { with } \\
\text { HOFEM (\%) }\end{array}$ & $\mathrm{R}-\mathrm{R}$ & HOFEM & HFEM & $\begin{array}{l}\text { Difference } \\
\text { with } \\
\text { R-R }(\%) \\
\end{array}$ & $\begin{array}{c}\text { Difference } \\
\text { with } \\
\text { HOFEM (\%) } \\
\end{array}$ \\
\hline \multirow{3}{*}{$\mathrm{S}-\mathrm{S}$} & $\omega_{1}(\mathrm{rad} / \mathrm{s})$ & 1269.2 & 1270.44 & 1270.44 & 0.10 & 0.00 & 1270 & 1271.06 & 1271.06 & 0.08 & 0.00 \\
\hline & $\omega_{2}(\mathrm{rad} / \mathrm{s})$ & 5079.9 & 5084.81 & 5084.92 & 0.10 & 0.00 & 5080 & 5084.23 & 5084.34 & 0.09 & 0.00 \\
\hline & $\omega_{3}(\mathrm{rad} / \mathrm{s})$ & 11429 & 11440.43 & 11442.84 & 0.12 & 0.02 & 11430 & 11439.52 & 11441.93 & 0.10 & 0.02 \\
\hline \multirow[b]{2}{*}{$\mathrm{C}-\mathrm{C}$} & $\omega_{1}(\mathrm{rad} / \mathrm{s})$ & 2875.9 & 2878.71 & 2878.72 & 0.10 & 0.00 & 2879 & 2881.34 & 2881.35 & 0.08 & 0.00 \\
\hline & $\omega_{2}(\mathrm{rad} / \mathrm{s})$ & 7931.3 & 7938.96 & 7939.44 & 0.10 & 0.01 & 7936 & 7942.54 & 7943.03 & 0.09 & 0.01 \\
\hline $\mathrm{F}-\mathrm{C}$ & $\omega_{3}(\mathrm{rad} / \mathrm{s})$ & 7881.6 & 7889.28 & 7889.97 & 0.11 & 0.01 & 7939.1 & 7945.68 & 7946.46 & 0.09 & 0.01 \\
\hline
\end{tabular}


Table A.II shows the assembly algorithm of $\mathrm{K}$ and $\mathrm{M}$ matrices in CFEM for a composite beam divided into 6 elements. Each element has 2 nodes and each node has 2 degrees of freedom (wi and $\theta i$ ). Each color represents an element's $k$ or $m$ matrix. In the areas where two matrices overlap, the two corresponding matrix elements are being added together.

Table A.II. Assembly algorithm of $\mathrm{K}$ and $\mathrm{M}$ matrices in CFEM

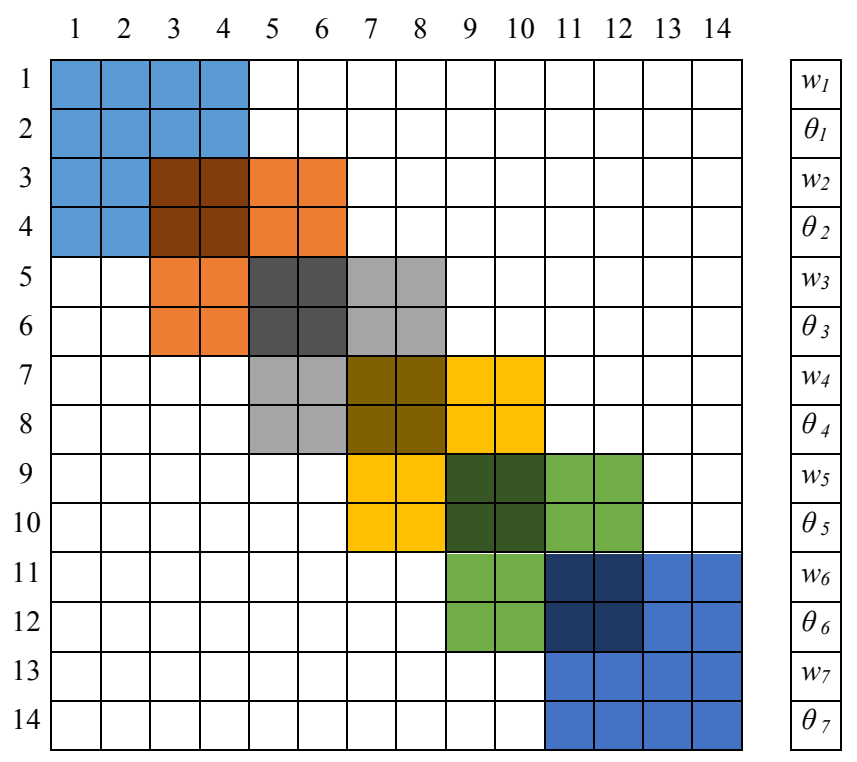

In HFEM with one trigonometric term, each element's stiffness $(\mathrm{k})$ or mass $(\mathrm{m})$ matrix is a $5 \times 5$ matrix. The fifth row and the fifth column are the hierarchical terms corresponding to hierarchical non-physical degree of freedom (Ai) to complete the form of a square matrix. As it is shown in Table A.III, the global stiffness (K) and mass (M) matrices are assembled in the same manner as CFEM for the first four rows and columns and the hierarchical terms fill the rest of the matrix.

Table A.III. Assembly algorithm of K and M matrices in HFEM with one hierarchical term
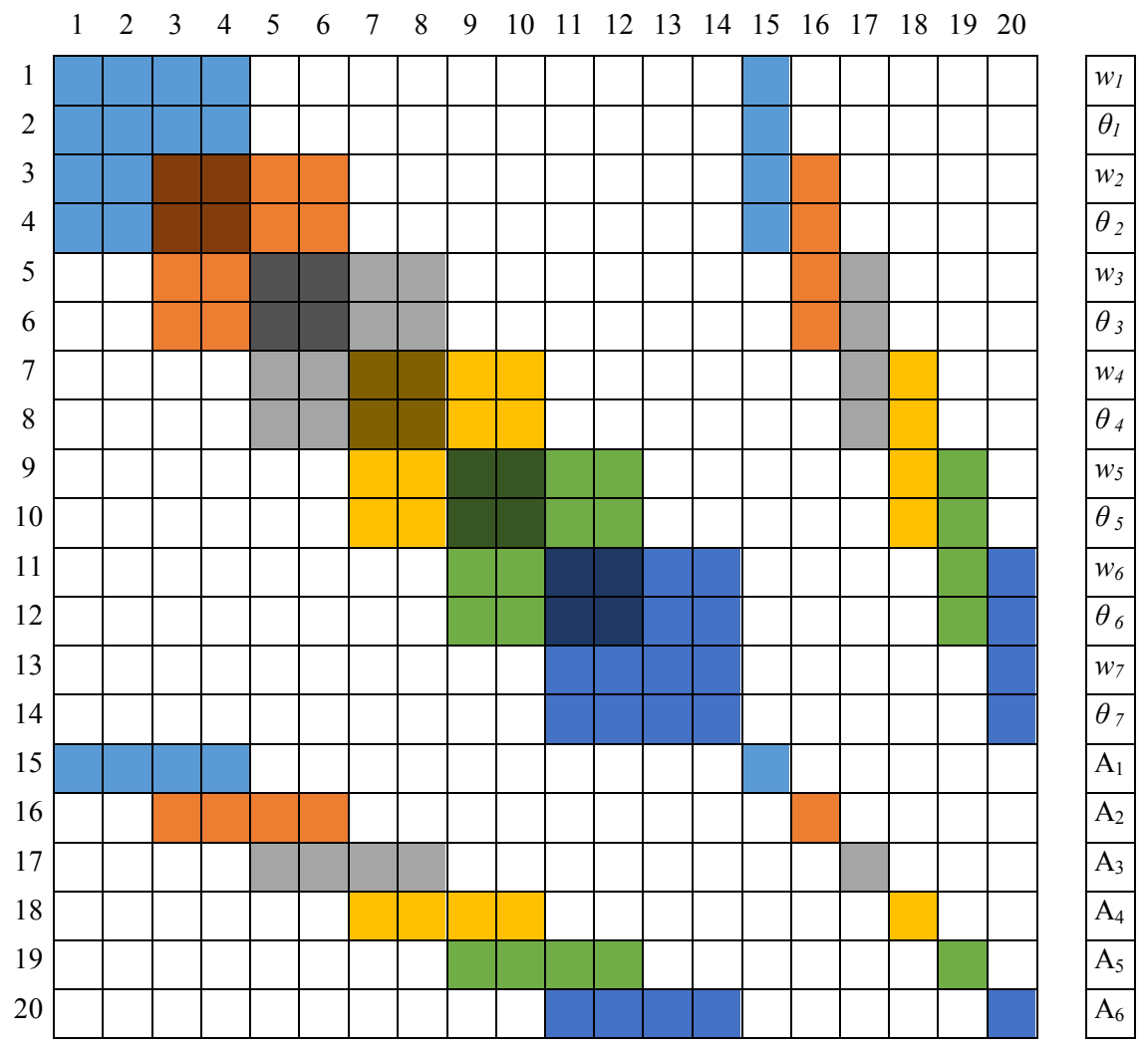